\title{
Total energy intake according to the level of skeletal muscle mass in Korean adults aged 30 years and older: an analysis of the Korean National Health and Nutrition Examination Surveys (KNHANES) 2008-2011
}

\author{
Bo Young Jang and So Young $\mathrm{Bu}^{\S}$ \\ Department of Food and Nutrition, Daegu University, 201 Daegudae-ro, Gyeongsan-si, Gyeongbuk 38453, Korea
}

BACKGROUND/OBJECTIVES: Since gain or loss of skeletal muscle mass is a gradual event and occurs due to a combination of lifestyle factors, assessment of dietary factors related to skeletal muscle is complicated. The aim of this study was to investigate the changes in total energy intake according to the level of skeletal muscle mass.

SUBJECTS/METHODS: A total of 8,165 subjects $\geq 30$ years of age from the Korean National Health and Nutrition Examination Surveys (KNHANES) 2008-2011 were included in the analysis, and multivariate-adjusted regression analyses were performed to analyze the association of the quartiles of sarcopenia index (SI) with energy intake of the study population after adjusting for age and metabolic parameters.

RESULTS: The increase in SI quartile was in proportion to the gradual decrease in systemic lipids and the anthropometric measurement of fat accumulation $(P<0.001)$. Subjects in higher SI quartiles tended to consume more total energy and energy-producing nutrients than those in lower quartiles $(P<0.001)$. After age, body weight, alcohol consumption, and metabolic parameters were adjusted in the analysis, total energy intake gradually increased according to the increase in SI quartile, and the association between total energy intake and SI was more pronounced in men. However, the risk (odd ratio) of having a low SI was not affected by any single macronutrient intake.

CONCLUSION: In this study, total energy intake was positively associated with SI and relative skeletal mass in both men and women. However, no significant association or a weak association was observed between any single macronutrient intake and skeletal muscle mass. The data indicated that acquiring more energy intake within the normal range of energy consumption may help to maintain skeletal muscle mass.

Nutrition Research and Practice 2018;12(3):222-232; https://doi.org/10.4162/nrp.2018.12.3.222; plSSN 1976-1457 elSSN 2005-6168

Keywords: Muscles, energy intake, aging, sarcopenia, gender

\section{INTRODUCTION}

Due to an aging population, maintaining optimal musculoskeletal health has become necessary to ensure healthy aging in conjunction with reducing the medical and/or social costs of age-related diseases as well as complications related to physical activities $[1,2]$. Even in young adults, retaining skeletal muscle mass is related to disease susceptibility and affects responses to medical therapies for many ailments such as diabetes, cardiovascular disease, and cancer [3-6]. Previous findings have suggested that building or maintaining skeletal muscle mass is influenced by metabolic conditions, physical activity, nutritional status, and/or diet $[7,8]$. Of these, the causal relationship between nutrient intake and skeletal muscle mass is complicated by metabolic conditions that co-interact with nutritional status $[9,10]$. For example, high protein intake has been shown to reduce insulin sensitivity [9] and is associated with an increased risk of developing insulin resistance and type 2 diabetes (T2D), the condition that leads to the disintegration of skeletal muscle [11]. Moreover, alteration of fat-free mass was shown to be positively correlated with 24-h energy intake before and after exercise in overweight and obese subjects $[12,13]$.

Although the importance of adequate muscle mass to health outcomes is relatively well-established, no research has specifically examined total caloric intake and types of macronutrient intake. Previous studies have been conducted on subjects with metabolic dysfunction (for example, overweight or obese subjects with average body mass index (BMI) of $22-37 \mathrm{~kg} / \mathrm{m}^{2}$ ) [14-16], under extreme conditions such as substantial loss of muscle mass (for

\footnotetext{
This research was supported by the Daegu University General Research Grant, 2015 (20150304).

${ }^{\S}$ Corresponding Author: So Young Bu, Tel. 82-53-850-6832, Fax. 82-53-210-8765, Email. busy@daegu.ac.kr

Received: November 28, 2017, Revised: March 26, 2018, Accepted: April 12, 2018

This is an Open Access article distributed under the terms of the Creative Commons Attribution Non-Commercial License (http://creativecommons.org/licenses/by-nc/3.0/) which permits unrestricted non-commercial use, distribution, and reproduction in any medium, provided the original work is properly cited.
} 
example, subjects with sarcopenia) $[6,7,16]$, or under circumstances of extreme physical training (for example, athletes) $[8,17]$. Thus, no study has investigated the association of skeletal muscle with energy intake using a population-based dataset or subject pools with a normal body weight or BMI. Also assessing the effect of type of energy nutrient, carbohydrate or fat intake on skeletal muscle mass was shaded due to the proportional increase or decrease of the nutrients intake to the amount of total energy intake [18] and their relation to the risk of metabolic diseases [19-21].

Skeletal muscle loss or gain in a healthy population generally takes a few months to years [22]. Hence, assessing health or nutritional status during stages of muscle possession rather than substantial reduction (i.e. sarcopenia vs non-sarcopenia) is a more reliable approach to understanding the relationship between nutrient intake and skeletal muscle mass. Further, the variation curve of skeletal muscle mass across a lifetime differs by gender $[23,24]$. Hence, alteration of skeletal muscle mass in response to caloric or nutrient intake will differ by gender, and separate analyses for men and women are necessary to investigate health outcomes in response to different total energy intakes.

Therefore, the aim of this study was to investigate alteration of total energy intake and type of energy-producing nutrient intake according to the level of skeletal muscle mass as well as whether any gender difference exists in these relationships.

\section{SUBJECTS AND METHODS}

\section{Study subjects}

In this study, data from the Korean National Health and Nutrition Examination Surveys (KNHANES) 2008, 2009, 2010, and 2011 were utilized and pooled for analysis. The KNHANES is a nationwide survey conducted by the Korean Centers for Disease Control and Prevention in the Ministry of Health and Welfare in order to examine the health and nutritional status of the Korean population. Initially, 37,753 subjects were identified from the KNHANES 2008-2011. In the first screening, 23,526 subjects aged 30 years or older were selected (Fig. 1). Subjects who did not have dual-energy X-ray absorptiometry (DXA) or BMl data were excluded $(n=7,154)$. Subjects with incomplete lab data or dietary record $(n=2,826)$ and on-going medication $(n=697)$ were excluded. Subjects whose dietary record was different than usual diet $(n=4,083)$ as well as subjects whose total energy consumption was lower than resting metabolic energy $(n=186)$ or much higher $(>1.5$-fold) than Korean dietary reference intake (KDRI) [25] $(n=415)$ were excluded. This study ultimately analyzed data from 8,165 subjects comprised of men $(n=3,433)$ and women $(n=4,732)$. The Institutional Review Board of the Korea Center for Disease Control and Prevention reviewed and approved the KNHANES (IRB Nos. 2008-04EXP01-C, 2009-01CON-03-2C, 2010-02CON-21, and 2011-02CON-06-C).

Assessment of anthropometric measurement and lean body mass $\mathrm{BMl}$ was generated by dividing weight $(\mathrm{kg})$ by square height $\left(\mathrm{m}^{2}\right)$. A whole-body dual-energy X-ray absorptiometry (DXA) examination was performed using a fan-beam densitometer (Discovery-W, Hologic Inc., Bedford, MA, USA) to obtain parameters necessary for calculation of skeletal muscle mass.

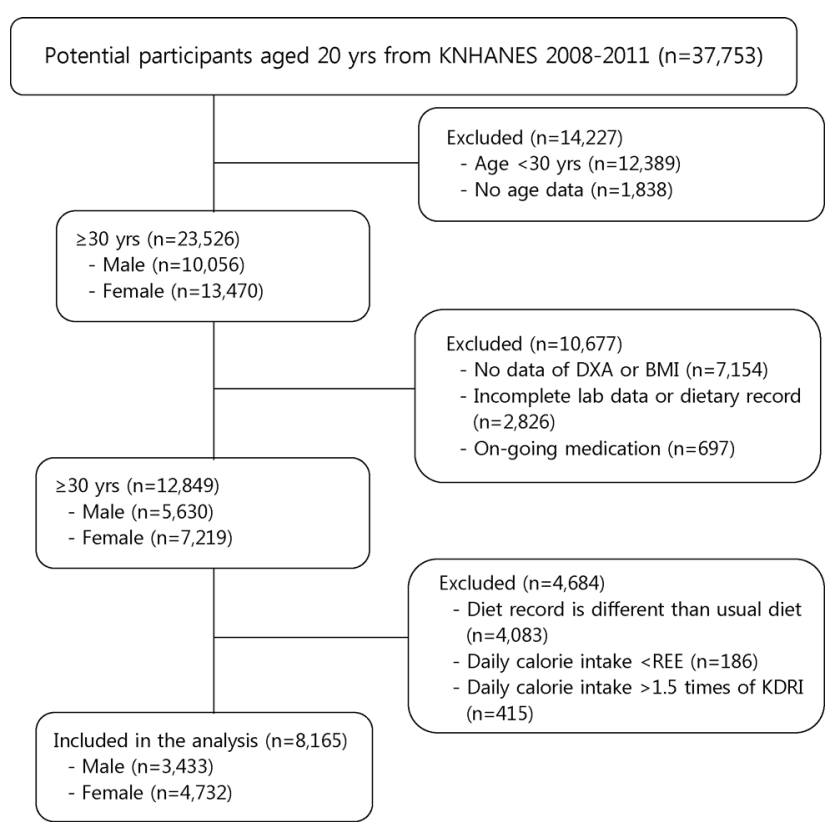

Fig. 1. Flow diagram of subject inclusion and exclusion. KNHANES, Korean National Health and Nutrition Examination Surveys; DXA, Dual-energy X-ray absorptiometry; BMI Body mass index; REE, Resting energy expenditure; KDRI, Korean dietary reference intake.

The accuracy of the DXA instrument used for calibration in the KNHANES has been reported in previous studies [26,27]. Total lean body mass was acquired from all regions of the body where skeletal muscle was attached (i.e. head, trunk, arms, and legs). Appendicular lean body mass was acquired by combining the lean body masses of both arms and legs.

\section{Calculation of sarcopenia index (SI)}

In this study, we categorized study subjects by the quartile level of the sarcopenia index (SI), which provides a good estimate of the amount of skeletal muscle mass relative to body size [28]. Calculation of SI was performed according to a previous report from the Foundation for the National Institutes of Health [28]. The value of SI was obtained by dividing the amount of appendicular skeletal mass by the BMl; $\mathrm{SI}(\%)=$ total appendicular muscle mass $(\mathrm{kg}) /$ body weight $(\mathrm{kg}) \times 100$.

\section{Assessment of dietary intake}

Subjects' dietary intake data from a 24-h dietary recall were used to assess caloric and nutrient intakes. Subjects were also asked whether or not their dietary intake on record in their 24-h dietary recall was similar to their usual diet. To minimize variation in the cross-sectional dietary assessment, only the dietary data that were similar to a subject's typical dietary intake were analyzed. Frequency of alcohol consumption was converted into number of servings per day and classified into two categories: " $\geq 1-2$ serving/d", which corresponds to $\geq 2$ servings/d for men and $\geq 1.5$ servings/d for women, or " $<1-2$ servings/d", which corresponds to $<2$ servings/d for men and $<1.5$ servings/d for women. Caloric intake from alcohol was calculated by multiplying the number of servings/d by 64 $\mathrm{kcal} /$ serving, which is an average of kcal generated from one serving of alcoholic beverages [29]. 
Measurement of biochemical indicators and assessment of other covariates

Total cholesterol, total triglyceride, fasting plasma glucose, and fasting insulin were measured using a chemistry analyzer (Hitachi 7600, Hitachi, Tokyo, Japan). Type of physical activity was categorized as active or non-active as follows: participants who reported doing mild or mid-strength physical activity for at least 5 days a week for a minimum of 30 minutes were coded as "active" while those who did not meet these criteria were classified as "non-active". The participants were asked about their smoking status and were classified as either "smoker" if they reported ever having smoked more than five packs of cigarettes during their lifetime or as "non-smoker" if they reported no history of smoking.

\section{Statistical analysis}

Since the SI data were slightly skewed to the left as absolute values, all SI values were log-transformed to obtain a normal distribution. The data were then stratified by quartiles of log-transformed values of the SI to compare the differences in health-related variables and nutrition intake according to the level of skeletal muscle mass. The range of values for each $\mathrm{SI}$ quartile was as follows: for men, first quartile (Q1): $\mathrm{SI}<0.82$, second quartile (Q2): $0.82 \leq \mathrm{SI}<0.89$, third quartile (Q3): 0.89 $\leq \mathrm{SI}<0.97$, and fourth quartile (Q4): $0.97 \leq$ Sl. For women, Q1: $\mathrm{SI}<0.55$, Q2: $0.55 \leq \mathrm{S} \mathrm{I}<0.61, \mathrm{Q} 3: 0.61 \leq \mathrm{SI}<0.67$, and Q4: 0.67 $\leq \mathrm{Sl}$. Q1 values for both men and women were nearly equivalent to the criteria values of sarcopenia $(<0.789$ for men, $<0.512$ for women) [28].

The data values were presented as follows: continuous variables were expressed as mean, and standard errors and categorical variables were expressed as frequency with percentages. For the comparison of continuous variables among the SI quartiles, analysis of variance (ANOVA) was performed after weighting all values without adjustment. The distribution difference in the categorical variables was analyzed using the Rao-Scott chi-square test. All analyses were performed as a complex-sampling analysis, and a domain code was allotted to a subgroup of interest to provide less-biased estimates.

Linear regression models were created to characterize the association of nutrient intake with quartile of the SI. Before designing the linear regression model, collinearity among each independent variable was tested. A simple correlation test was performed to ensure that no strong (more than $80 \%$ ) correlation existed between the co-variants (for example, age and $\mathrm{SI}$ ) in the linear regression model. The values of variance inflation factors (VIF) were calculated to assess the degree of collinearity (e.g. age vs. SI, VIF: 1.02) among the variables in the regression model. Height and weight are well-known confounding factors in assessing nutrient intake and skeletal muscle mass; these two variables had a strong correlation, so only the weight was adjusted in the analysis. Carbohydrate, fat, and protein intakes were adjusted for average total energy intake (kcal) by adding residual values of carbohydrates, fat, and protein before the values were incorporated into the linear regression model. All analyses were performed on men and women separately; therefore, sex was not double-adjusted in the model. Using the linear regression model beta coefficient, $95 \%$ confidence interval
(Cl) for total energy intake and energy-producing nutrients according to the SI quartiles were estimated by setting the lowest SI quartile as the reference.

Logistic regression analysis was performed to estimate the odds ratio, $95 \% \mathrm{Cls}$, and $P$ for trend for risk of low skeletal muscle mass by tertile level of total energy and carbohydrate intakes. The highest tertile group was taken as the reference group in male and female subjects separately, and key covariates (age, physical activity, and smoking) were adjusted in the logistic regression model. The range of total energy intake values for each tertile was as follows: for men, first tertile (T1): total energy intake $<1,753.5 \mathrm{kcal}$, second tertile (T2): 1,753.5 $\mathrm{kcal} \leq$ total energy intake $<2,278.9 \mathrm{kcal}$, third tertile (T3): 2,278.9 kcal $\leq$ total energy intake, for women, T1: total energy intake $<1,350.0 \mathrm{kcal}, \mathrm{T} 2: 1,350.0 \mathrm{kcal} \leq$ total energy intake < 1,768.4 kcal, T3: 1,768.4 kcal $\leq$ total energy intake. The range of carbohydrate intake values for each tertile was as follows: for men, T1: carbohydrate intake <313.0 g, T2: $313.0 \mathrm{~g} \leq$ total energy intake <359.3 g, T3: $359.3 \mathrm{~g} \leq$ carbohydrate intake, for women, T1: carbohydrate intake <288.2 g, T2: $288.2 \mathrm{~g} \leq$ carbohydrate intake <327.1, T3: $327.1 \mathrm{~g} \leq$ carbohydrate intake.

SAS software version 9.4 (SAS Institute Inc., Cary, NC, USA) was used for all statistical analyses in this study. The statistical significance of the data was set at $P<0.05$.

\section{RESULTS}

\section{Anthropometric and biochemical characteristics of the study subjects}

The anthropometric characteristics of the study subjects are presented in Table 1. Average ages of men and women at Q1 were 59.3 and 59.9 years, respectively. The age of the study subjects decreased as SI quartile increased in both men and women $(P<0.0001)$. A large proportion of the aged subjects was in the lowest $\mathrm{SI}$ quartile, and the proportion of aged subjects decreased as SI quartile increased $(P<0.0001)$. Both men and women in the higher $\mathrm{SI}$ quartile had higher values for height, total skeletal muscle mass, and appendicular muscle mass than those in the lowest SI quartile. Men showed increased body weight with increasing SI $(P<0.0001)$ while women showed no significant change in body weight with increasing $\mathrm{SI}$, indicating that weight gain in men tended to accompany more muscle gain than in women. Subjects in higher SI quartiles had a lower waist circumference than those in the lower SI quartiles.

Biochemical indicators are also presented in Table 1. While systolic blood pressure was reduced as SI increased in both men and women, diastolic blood pressure did not consistently increase across $\mathrm{SI}$ quartiles. In the analysis of biochemical parameters, levels of total blood triglycerides, fasting blood glucose, and insulin resistance index scores (HOMA-IR) were proportional to an increase in SI quartile $(P<0.0001)$. Total cholesterol also decreased with increasing $\mathrm{SI}$ in women. For men, however, the mean value of total cholesterol fluctuated across the quartiles. The distribution of subjects who were regularly physically active was not significantly different among the SI quartiles in both men $(P=0.0917)$ and women $(P=$ 0.6320). The ratios of smokers in each quartile were $64.2 \%$ (Q1) to $72.7 \%(\mathrm{Q} 4)$ in men $(P=0.0181)$ and $8.5 \%(\mathrm{Q} 1)$ to $8.9 \%(\mathrm{Q} 2$ 


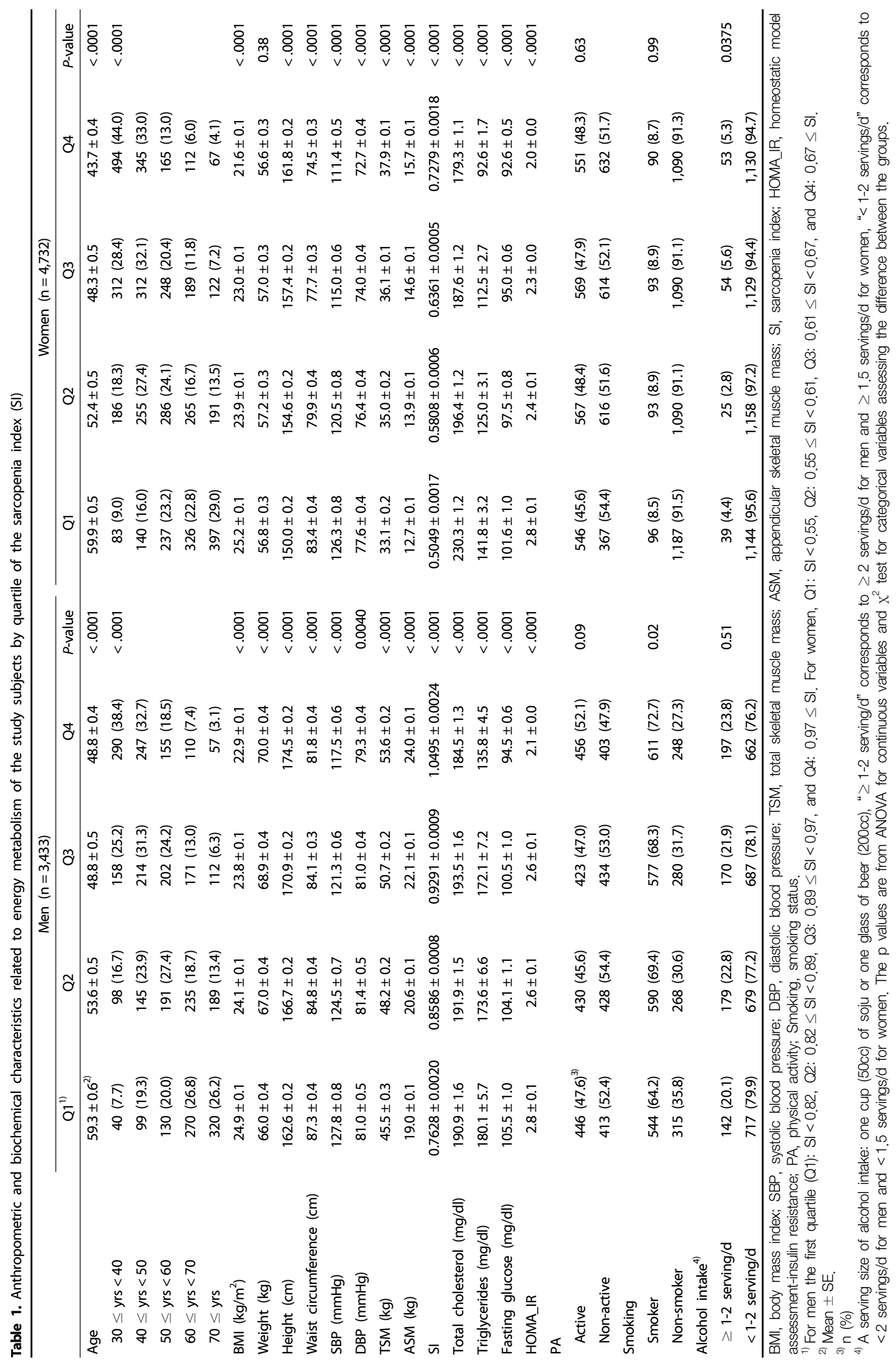




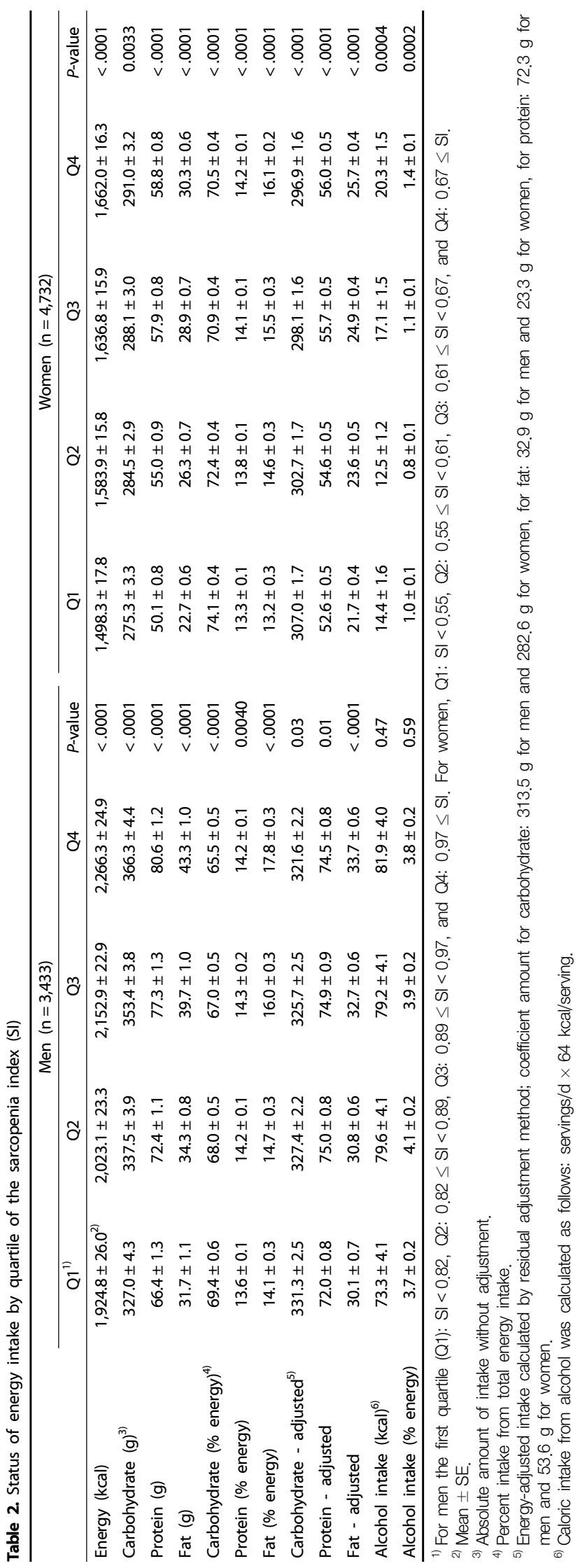


Table 3. Estimated change in total energy intake according to quartile of the sarcopenia index (SI)

\begin{tabular}{|c|c|c|c|}
\hline & Men & Women & Total \\
\hline \multicolumn{4}{|l|}{ Model $\mathrm{I}^{1)}$} \\
\hline $\mathrm{R} 2$ & 0.101 & 0.0385 & 0.1608 \\
\hline Q1 & $\operatorname{Ref}^{4)}$ & Ref & Ref \\
\hline Q2 & $45.1(-20.2,110.4)$ & $51.0(5.5,96.5)^{*}$ & $57.2(17.7,96.7)^{* * * *}$ \\
\hline Q3 & $128.2(60.7,195.7)^{* * *}$ & $85.0(38.7,131.2)^{* * *}$ & $121.1(78.8,163.3)^{* * * *}$ \\
\hline Q4 & $201.2(128.6,273.7)^{* * * *}$ & $90.6(38.8,142.4)^{* * *}$ & $165.6(120.3,210.9)^{* * * *}$ \\
\hline$P$ for trend & $<.0001$ & 0.0018 & $<.0001$ \\
\hline \multicolumn{4}{|l|}{ Model $\|^{2)}$} \\
\hline $\mathrm{R} 2$ & 0.1044 & 0.0415 & 0.1742 \\
\hline $\mathrm{Q} 1^{3)}$ & Ref & Ref & Ref \\
\hline Q2 & $47.6(-17.2,112.3)$ & $50.2(5.2,95.1)^{*}$ & $51.9(12.6,91.2)^{* *}$ \\
\hline Q3 & $128.9(61.4,196.5)^{* * *}$ & $81.1(35.1,127.2)^{* * *}$ & $115.0(72.3,157.7)^{* * * *}$ \\
\hline Q4 & $205.7(132.7,278.8)^{* * *}$ & $84.1(31.8,136.4)^{* *}$ & $153.9(107.9,199.9)^{* * * *}$ \\
\hline$P$ for trend & $<.0001$ & 0.0038 & $<.0001$ \\
\hline
\end{tabular}

Beta coefficient with $95 \%$ confidence interval is shown.

${ }^{1)}$ Model I: adjusted for age, body weight and energy from alcohol intake.

${ }^{2}$ ) Model II: model I + physical activity + levels of total cholesterol and fasting glucose + smoking status

3) For men the first quartile (Q1): $\mathrm{SI}<0.82$, Q2: $0.82 \leq \mathrm{SI}<0.89$, Q3: $0.89 \leq \mathrm{SI}<0.97$, and Q4: $0.97 \leq \mathrm{SI}$. For women, Q1: SI<0.55, Q2: $0.55 \leq \mathrm{SI}<0.61$, Q3: $0.61 \leq$ $\mathrm{SI}<0.67$, and Q4: $0.67 \leq \mathrm{SI}$.

4) Beta coefficient in linear trend analysis with energy intake and Sl: for men $112.3 \mathrm{kcal} / \mathrm{SI}\left(0.1 \mathrm{~m}^{2}\right)$, for women $\left.43.9 \mathrm{kcal} / \mathrm{SI}(0.1 \mathrm{~m})^{2}\right)$.

${ }^{\star} P<0.05,{ }^{* *} P<0.01,{ }^{\star * *} P<0.001$ compared to reference group of sarcopenia index (Q1) within same sex or total subjects.

Table 4. Estimated change in carbohydrate intake according to quartile of the sarcopenia index (SI)

\begin{tabular}{|c|c|c|c|}
\hline & Men & Women & Total \\
\hline \multicolumn{4}{|l|}{ Model I") } \\
\hline $\mathrm{R} 2$ & 0.1168 & 0.1103 & 0.0894 \\
\hline Q1 & Ref & Ref & Ref \\
\hline Q2 & $1.6(-4.7,7.8)$ & $2.7(-1.5,6.9)$ & $3.0(-1.0,1.7)$ \\
\hline Q3 & $3.8(-2.4,10.0)$ & $2.9(-1.3,7.2)$ & $4.7(0.7,8.7)^{*}$ \\
\hline Q4 & $3.5(-3.1,10.1)$ & $6.7(2 \cdot 0,11.3)^{* *}$ & $6.8(2.7,11.0)^{* *}$ \\
\hline$P$ for trend & 0.61 & 0.05 & 0.01 \\
\hline \multicolumn{4}{|l|}{ Model $\|^{2)}$} \\
\hline $\mathrm{R} 2$ & 0.1202 & 0.1133 & 0.1052 \\
\hline $\mathrm{Q} 1^{3)}$ & Ref & Ref & Ref \\
\hline Q2 & $1.6(-4.7,7.9)$ & $2.7(-1.5,6.9)$ & $2.4(-1.6,6.4)$ \\
\hline Q3 & $3.9(-2.3,10.1)$ & $2.7(-1.5,7.0)$ & $4.1(0.1,8.1)$ \\
\hline Q4 & $3.6(-3.2,10.3)$ & $6.2(1.6,10.9)$ & $5.7(1.5,9.9)$ \\
\hline$P$ for trend & 0.61 & 0.07 & 0.06 \\
\hline
\end{tabular}

Beta coefficient with $95 \%$ confidence interval is shown.

${ }^{1)}$ Model I: adjusted for age, body weight and energy from alcohol intake.

2) Model II: model I + physical activity + the level of total cholesterol and fasting glucose + smoking status.

${ }^{3)}$ For men the first quartile (Q1): $\mathrm{SI}<0.82, \mathrm{Q} 2: 0.82 \leq \mathrm{SI}<0.89, \mathrm{Q} 3: 0.89 \leq \mathrm{SI}<0.97$, and $\mathrm{Q} 4: 0.97 \leq \mathrm{SI}$. For women, Q1: $\mathrm{SI}<0.55, \mathrm{Q} 2: 0.55 \leq \mathrm{SI}<0.61, \mathrm{Q} 3$ : $0.61 \leq$ $\mathrm{SI}<0.67$, and Q4: $0.67 \leq \mathrm{SI}$

${ }^{\star} P<0.05,{ }^{* *} P<0.01$ compared to reference group of sarcopenia index (Q1) within same sex or total subjects.

and Q3) in women $(P=0.9901)$. The mean amount of alcohol consumption in men was higher than that in women, but the distribution of high alcohol consumption ( $\geq 1-2$ servings/d) across the quartiles of SI was not statistically significant in men.

Status of nutrient intake by quartile of sarcopenia index

The absolute values for total energy and nutrient intakes increased as SI quartile increased (Table 2). Intake ratios of carbohydrates to total energy in Q1 of SI in men and women were $69.4 \%$ and $74.1 \%$, and the ratios significantly decreased to $65.5 \%$ and $70.5 \%$ in Q4, respectively. Intake ratios of protein to total energy in Q1 were $13.6 \%$ and $13.3 \%$ in men $(P=0.0040)$ and women $(P<0.0001)$ while intake ratios of fat to total energy in Q1 were $14.1 \%$ and $13.2 \%$ in men $(P<0.0001)$ and women, respectively $(P<0.0001)$. Intake ratios of fat relative to total energy intake increased within a narrow range as SI quartile increased. Energy-adjusted values of carbohydrate intake decreased from $331.3 \mathrm{~g}(\mathrm{Q} 1)$ to $321.6 \mathrm{~g}(\mathrm{Q} 4)$ for men $(P=0.0281)$ and from $307.0 \mathrm{~g}(\mathrm{Q} 1)$ to $296.9 \mathrm{~g}(\mathrm{Q} 4)$ for women $(P<0.0001)$ as SI quartile increased. In women, protein intake after adjustment of total energy intake gradually increased from $52.6 \mathrm{~g}$ (Q1) to $56.0 \mathrm{~g}$ (Q4) for women as SI quartile increased. In men, average 
Table 5. Estimated change in fat intake according to quartile of the sarcopenia index (SI)

\begin{tabular}{|c|c|c|c|}
\hline & Men & Women & Total \\
\hline \multicolumn{4}{|l|}{ Model $I^{1)}$} \\
\hline $\mathrm{R} 2$ & 0.0883 & 0.124 & 0.1175 \\
\hline Q1 & Ref & Ref & Ref \\
\hline Q2 & $-1.2(-2.9,0.5)$ & $-0.6(-1.8,0.5)$ & $-0.7(-1.7,0.3)$ \\
\hline Q3 & $-1.0(-2.8,0.8)$ & $-0.8(-1.9,0.4)$ & $-0.5(-1.6,0.5)$ \\
\hline Q4 & $-1.5(-3.3,0.4)$ & $-1.5(-2.8,-0.2)$ & $-1.0(-2.1,0.1)$ \\
\hline$P$ for trend & 0.42 & 0.14 & 0.31 \\
\hline \multicolumn{4}{|l|}{ Model $\|^{2)}$} \\
\hline $\mathrm{R} 2$ & 0.0913 & 0.1258 & 0.133 \\
\hline $\mathrm{Q} 1^{3)}$ & Ref & Ref & Ref \\
\hline Q2 & $-1.2(-2.9,0.5)$ & $-0.6(-1.7,0.5)$ & $-0.8(-1.9,0.2)$ \\
\hline Q3 & $-1.1(-2.9,0.7)$ & $-0.7(-1.8,0.5)$ & $-0.7(-1.7,0.4)$ \\
\hline Q4 & $-1.5(-3.4,0.3)$ & $-1.3(-2.6,-0.1)$ & $-1.2(-2.3,-0.1)$ \\
\hline$P$ for trend & 0.38 & 0.23 & 0.17 \\
\hline
\end{tabular}

Beta coefficient with 95\% confidence interval is shown.

1) Model I: adjusted for age, body weight and energy from alcohol intake.

2) Model II: model I + physical activity + the level of total cholesterol and fasting glucose + smoking status

${ }^{3)}$ For men the first quartile (Q1): $\mathrm{Sl}<0.82, \mathrm{Q} 2: 0.82 \leq \mathrm{SI}<0.89$, Q3: $0.89 \leq \mathrm{Sl}<0.97$, and $\mathrm{Q} 4: 0.97 \leq \mathrm{Sl}$. For women, Q1: $\mathrm{Sl}<0.55, \mathrm{Q} 2: 0.55 \leq \mathrm{SI}<0.61, \mathrm{Q} 3$ : $0.61 \leq$ $\mathrm{SI}<0.67$, and Q4: $0.67 \leq \mathrm{SI}$.

Table 6. Estimated change in protein intake according to quartile of the sarcopenia index (SI)

\begin{tabular}{|c|c|c|c|}
\hline & Men & Women & Total \\
\hline \multicolumn{4}{|l|}{ Model I $^{1)}$} \\
\hline $\mathrm{R} 2$ & 0.0229 & 0.0492 & 0.1152 \\
\hline Q1 & Ref & Ref & Ref \\
\hline Q2 & $2.1(0.1,4.1)$ & $0.2(-1.1,1.5)$ & $1.5(0.2,2.9)$ \\
\hline Q3 & $0.9(-1.5,3.3)$ & $0.3(-1.1,1.8)$ & $1.4(-0.1,2.8)$ \\
\hline Q4 & $-0.2(-2.4,2.1)$ & $-0.4(-2.0,1.1)$ & $0.7(-0.8,2.2)$ \\
\hline$P$ for trend & 0.11 & 0.73 & 0.12 \\
\hline \multicolumn{4}{|l|}{ Model $\|^{2)}$} \\
\hline $\mathrm{R} 2$ & 0.0289 & 0.0497 & 0.1448 \\
\hline $\mathrm{Q} 1^{3)}$ & Ref & Ref & Ref \\
\hline Q2 & $2.2(0.2,4.2)$ & $0.2(-1.1,1.5)$ & $1.2(-0.1,2.6)$ \\
\hline Q3 & $0.9(-1.5,3.3)$ & $0.4(-1.1,1.8)$ & $1.1(-0.4,2.5)$ \\
\hline Q4 & $-0.2(-2.4,2.0)$ & $-0.3(-1.9,1.2)$ & $0.1(-1.4,1.6)$ \\
\hline$P$ for trend & 0.08 & 0.77 & 0.15 \\
\hline
\end{tabular}

Beta coefficient with 95\% confidence interval is shown.

1) Model I: adjusted for age, body weight and energy from alcohol intake.

${ }^{2}$ Model II: model I + physical activity + the level of total cholesterol and fasting glucose + smoking status.

3) For men the first quartile (Q1): $\mathrm{SI}<0.82, \mathrm{Q} 2: 0.82 \leq \mathrm{SI}<0.89$, Q3: $0.89 \leq \mathrm{SI}<0.97$, and $\mathrm{Q} 4: 0.97 \leq \mathrm{SI}$. For women, Q1: $\mathrm{SI}<0.55$, Q2: $0.55 \leq \mathrm{SI}<0.61, \mathrm{Q} 3$ : $0.61 \leq$ $\mathrm{SI}<0.67$, and Q4: $0.67 \leq \mathrm{SI}$.

protein intake did not linearly increase throughout the SI quartiles. Energy-adjusted values of fat intake also increased as SI index increased from $30.1 \mathrm{~g}(\mathrm{Q} 1)$ to $33.7 \mathrm{~g} \mathrm{(Q4)} \mathrm{for} \mathrm{men} \mathrm{and}$ from $21.7 \mathrm{~g}(\mathrm{Q} 1)$ to $25.7 \mathrm{~g}$ (Q4) for women after adjustment of total energy intake. The range of values for energy from alcohol intake was $73.3 \mathrm{kcal}$ to $81.9 \mathrm{kcal}$ for men and $14.4 \mathrm{kcal}$ to $20.3 \mathrm{kcal}$ for women across SI quartiles. Intake ratios of alcohol to total energy intake were $3.7 \%$ to $4.1 \%$ for men and $0.8 \%$ to $1.4 \%$ for women throughout the quartiles. The data suggest that men consumed more energy from alcohol intake than women. However, the change in alcohol intake throughout the quartiles was not statistically significant in men.

Estimation of change in total energy and carbohydrate intake after adjustment of covariates

We examined the association of total energy and major nutrient intakes with SI by incorporating age, body weight, and alcohol intake as covariates into the linear regression model (Table 3-Table 5). The subjects in the highest SI quartiles had higher total energy intakes than those in the reference group (the lowest SI quartile) $(P<0.0001)$ (Table 3). When physical activity, smoking, and levels of blood lipids and fasting glucose 
Table 7. Adjusted ORs with $95 \% \mathrm{Cls}$ of low skeletal muscle mass by tertile of total energy intake

\begin{tabular}{|c|c|c|c|}
\hline & Men & Women & Total \\
\hline \multicolumn{4}{|l|}{ Model I" } \\
\hline T3 & 1.00 & 1.00 & 1.00 \\
\hline $\mathrm{T} 2$ & $1.14(0.97,1.35)^{*}$ & $1.16(1.00,1.35)$ & $1.15(1.04,1.28)$ \\
\hline $\mathrm{T} 1$ & $1.84(1.52,2.22)^{* * *}$ & $1.28(1.09,1.50)^{*}$ & $1.50(1.34,1.69)^{* * *}$ \\
\hline$P$ for trend & $<.0001$ & 0.01 & $<.0001$ \\
\hline \multicolumn{4}{|l|}{ Model $\|^{2)}$} \\
\hline T3 & 1.00 & 1.00 & 1.00 \\
\hline $\mathrm{T} 2$ & $1.18(1.00,1.40)^{*}$ & $1.16(0.99,1.34)$ & $1.16(1.05,1.29)$ \\
\hline $\mathrm{T} 1$ & $1.88(1.56,2.28)^{* * *}$ & $1.25(1.06,1.47)^{*}$ & $1.51(1.34,1.70)^{* * * *}$ \\
\hline$P$ for trend & $<.0001$ & 0.02 & $<.0001$ \\
\hline \multicolumn{4}{|l|}{ Model III) } \\
\hline$T 3^{4)}$ & 1.00 & 1.00 & 1.00 \\
\hline $\mathrm{T} 2$ & $1.04(0.82,1.31)^{*}$ & $1.02(0.81,1.27)$ & $1.06(0.86,1.30)$ \\
\hline $\mathrm{T} 1$ & $1.52(1.06,2.19)^{* *}$ & $0.99(0.72,1.37)$ & $0.96(0.83,1.10)$ \\
\hline$P$ for trend & 0.0047 & 0.96 & 0.25 \\
\hline
\end{tabular}

Odds ratio (OR) with 95\% confidence interval is shown.

${ }^{1)}$ Model I: adjusted for age, body weight, and energy from alcohol intake.

${ }^{2)}$ Model II: model I + physical activity + levels of total cholesterol and fasting glucose + smoking status.

3) Model III: model II + age $\times$ total energy intake.

4) Total energy intakes were categorized into tertile scale; for men, first tertile (T1): total energy intake $<1,753,5 \mathrm{kcal}$, second tertile (T2): $1,753,5 \mathrm{kcal} \leq$ total energy intake $<2,278.9 \mathrm{kcal}$, third tertile (T3): 2,278.9 kcal $\leq$ total energy intake, for women, T1: total energy intake $<1,350.0 \mathrm{kcal}$, T2: 1,350.0 kcal $\leq$ total energy intake $<1,768.4$ kcal, T3: $1,768.4 \mathrm{kcal} \leq$ total energy intake.

${ }^{\star} P<0.05,{ }^{* \star} P<0.01,{ }^{* \star *} P<0.001$ compared to reference group of total energy intake (T3) within same sex or total subjects.

Table 8. Adjusted ORs with $95 \% \mathrm{Cls}$ of low skeletal muscle mass by tertile of carbohydrate intake

\begin{tabular}{|c|c|c|c|}
\hline & Men & Women & Total \\
\hline \multicolumn{4}{|l|}{ Model I' } \\
\hline T3 & 1.00 & 1.00 & 1.00 \\
\hline $\mathrm{T} 2$ & $1.05(0.91,1.21)$ & $1.08(0.97,1.20)$ & $1.06(0.97,1.17)$ \\
\hline $\mathrm{T} 1$ & $1.09(0.93,1.29)$ & $1.18(1.02,1.37)$ & $1.15(1.03,1.28)^{*}$ \\
\hline$P$ for trend & 0.58 & 0.09 & 0.05 \\
\hline \multicolumn{4}{|l|}{ Model $\|^{2)}$} \\
\hline T3 & 1.00 & 1.00 & 1.00 \\
\hline $\mathrm{T} 2$ & $1.06(0.92,1.23)$ & $1.06(0.96,1.18)$ & $1.06(0.97,1.27)$ \\
\hline $\mathrm{T} 1$ & $1.09(0.92,1.29)$ & $1.16(1.00,1.35)$ & $1.14(1.02,1.27)$ \\
\hline$P$ for trend & 0.58 & 0.14 & 0.08 \\
\hline \multicolumn{4}{|l|}{ Model III) } \\
\hline $\mathrm{T}^{4)}$ & 1.00 & 1.00 & 1.00 \\
\hline $\mathrm{T} 2$ & $1.00(0.87,1.15)$ & $1.03(0.93,1.15)$ & $1.01(0.92,1.11)$ \\
\hline $\mathrm{T} 1$ & $1.10(0.93,1.30)$ & $1.12(0.97,1.31)$ & $1.10(0.98,1.23)$ \\
\hline$P$ for trend & 0.38 & 0.29 & 0.13 \\
\hline
\end{tabular}

Odds ratio (OR) with 95\% confidence interval is shown.

1) Model I: adjusted for age, body weight and energy from alcohol intake.

2) Model II: model I + physical activity + levels of total cholesterol and fasting glucose + smoking status

3) Model III: model II + age $\times$ total energy intake.

4) Energy adjusted total carbohydrate intake was categorized into tertile scale; for men, first tertile (T1): carbohydrate intake <313.0 g, second tertile (T2): $313.0 \mathrm{~g} \leq \mathrm{carbohydrate}$ intake < 359.3 g, third tertile (T3): $359.3 \mathrm{~g} \leq$ carbohydrate intake, for women, T1: carbohydrate intake < 288.2 g, T2: $288.2 \mathrm{~g} \leq$ carbohydrate intake < 327.1, T3: 327.1 $\mathrm{g} \leq$ carbohydrate intake.

* $P<0.05$ compared to reference group of carbohydrate intake (T3) within same sex or total subjects.

were added to the regression model, the change of total energy intake in the reference group (Q1) gradually increased as SI quartile increased (Table 3 ).

In men, there was no significant change in carbohydrate intake according to SI quartiles (Table 4). In women, the change in energy-adjusted carbohydrate intake in the reference group
(Q1) was statistically significant only in Q4 (model I in Table 4). However, the change in carbohydrate intake was $6.7 \mathrm{~g}$, which is equivalent to an energy intake of $27 \mathrm{kcal}$, and the trend was not significant (data not shown) after further adjustment for physical activity, smoking, and levels of blood lipids and fasting glucose (model II in Table 4). Differences in energy-adjusted 
fat and protein intake were not significant across the quartiles in both men and women after adjustment for age and other covariates (Table 5, Table 6).

\section{Relative risk of low skeletal muscle mass according to energy intake}

Since the quartile level of skeletal muscle mass was associated with alteration of total calorie intake in both men and women and was partially associated with carbohydrate intake in women, we further examined the relative risk of having low skeletal mass as predicted by the tertile level of total energy intake or carbohydrate intake. Table 7 shows the odd ratio (OR) for the risk of falling in the lowest quartile of $\mathrm{SI}$ in men and women on the basis of tertile scale of total energy intake after adjusting for confounding variables. Less total energy intake was associated with a higher prevalence of low skeletal muscle mass (Q1) in men (OR for the lowest tertile, 1.84; $95 \% \mathrm{Cl}, 1.52-2.22 ; P$ for trend, <.0001) and women (OR for the lowest tertile, 1.28; $95 \%$ $\mathrm{Cl}, 1.09-1.50 ; P$ for trend, 0.0112). When the interaction between age and energy intake was further adjusted in the model, the association between total energy intake and prevalence of low skeletal mass was still significant in men (OR for the lowest tertile, 1.52; $95 \% \mathrm{Cl}, 1.06-2.19 ; P$ for trend, 0.0047 ) but not in women. No association was observed between the tertile scale of carbohydrate intake and prevalence of low skeletal mass in men and women (Table 8).

\section{DISCUSSION}

Since skeletal muscle is responsible for a substantial portion of the body's total energy expenditure, supplying sufficient calories and nutrients may contribute to conservation of skeletal muscle mass $[8,18,19,30]$. In this study, we observed the association of skeletal muscle mass with total energy intake in both men and women, and the association was more pronounced in men than in women. However, carbohydrate intake showed a significant association with the highest quartile of skeletal muscle mass only in women. These data indicate that total energy intake is associated with skeletal muscle mass, although a gender difference exists in predicting the association of skeletal muscle mass with energy or macronutrient intake.

In the multivariate linear regression analysis with adjusting covariates, total energy intake gradually increased as SI quartile increased in both men and women. The relationship between skeletal muscle and energy intake was shown to be similar to the results of previous studies [30-31]. A meta-analysis by McNeil et al. [31] suggested that both acute energy intake and daily energy intake are strongly correlated with fat-free mass $(r=0.21$, 027). In obese adolescents, total skeletal muscle mass more strongly predicted subjects' total energy intake than did fat mass [30]. Our study also found that the estimated odds ratio for having a low skeletal mass in the tertile of lowest energy intake was higher than that in the highest tertile of total energy intake. However, no significant association was found between fat or protein intake and SI index. In this study, carbohydrate consumption accounted for more than $65 \%$ of subjects' total energy intake, and the intake amount was higher than the amount suggested by the KDRI [25], indicating a relatively lower ratio of protein and fat consumption. Hence, the effect of protein or fat consumption on skeletal muscle mass could not be detected due to the narrow range of variation in subjects' consumption of these nutrients.

In previous studies, carbohydrate intake was shown to be closely related to risk of metabolic syndrome, dyslipidemia, and obesity, which are profound confounding factors in the assessment of skeletal muscle mass [32-34]. For example, carbohydrate intake was shown to be associated with elevation of plasma low-density lipoprotein (LDL) cholesterol as well as reduction of high-density lipoprotein (HDL) [33]. However, the current study did not find any meaningful association between carbohydrate intake and skeletal muscle mass in the linear regression and logistic regression analyses. Previous studies have also suggested that the type rather than the amount of carbohydrate or food composition has more pronounced effects on health outcomes [34-36]. Taken together, our data indicate that elevation of the SI index can be predicted based on increased energy intake, whereas the association between SI and carbohydrate intake is not conclusive. A dietary pattern or sub-types within each macronutrient intake need to be clarified in future studies.

As noted in the results of the anthropometric and biochemical indices, a gradual decline in the proportion of elderly subjects was observed as the SI quartile increased, and an increased proportion of young subjects in the upper SI quartile seemed to cause an increase in the intakes of total energy and other major nutrients. This finding indicates that age is a significant contributing factor for estimating the association between nutrition intake and skeletal muscle mass. As expected, greater energy intake was shown to be associated with reduced incidence of low skeletal muscle mass. However, when the interaction between age and energy intake was incorporated into the logistic regression model, the association remained significant in men but not in women. Although this result may due to the age distribution pattern in women, physiological changes (for example, hormonal change) owing to aging strongly affected energy intake and skeletal muscle changes in women.

Despite having a direct relationship with skeletal muscle, the change in energy intake from the lowest to highest SI quartile was larger in men than in women. It has been consistently shown that men tend to eat more food and consume more total calories than women. However, the gender differences in health outcomes in response to different total energy intakes or expenditures between men and women have not been well reported. A longitudinal study on an elderly population recently demonstrated that decreased physical activity was associated with a decline in fat-free mass in men but not in women [16]. One interesting finding regarding gender differences in this study was that alcohol intake contributed up to $4 \%$ of total energy intake in men versus $1 \%$ in women, and such percent intake was equivalent to about $80 \mathrm{kcal}$ per day for men and 20 kcal per day for women. However, only women showed a significant association between increased alcohol intake and skeletal muscle mass. Since the intake patterns of macronutrients (high carbohydrate intake but relatively less intakes of protein and fat) were similar between men and women, the different distribution patterns of alcohol consumption or caloric intake 
from alcohol might contribute to gender differences in the association between total energy intake and skeletal muscle mass. Further analysis of dietary patterns contributing to total energy and macronutrient intakes may clarify gender differences in the association between energy intake and skeletal muscle mass.

The main limitation of this study is that the nutritional intakes of the study subjects were estimated from only one 24-h recall, and thus the data may not reflect daily variations in the nutrient intakes of the individual subjects. However, similarities in total dietary consumption as well as composition during the 24-h recall were checked for each subject during the nationwide survey, and only dietary data during the 24-h recall that were similar to the subjects' usual dietary patterns were included in the analysis. Thus, the screening process might have reduced daily variations in the data of total energy or nutrient intake within individuals. An analysis of indices reflecting long-term nutrient intake by different age groups may provide more precise information on the association of nutrient intake with skeletal muscle mass. Although this study demonstrated the association of total energy intake with $\mathrm{SI}$ and relative skeletal muscle mass, as many studies have already reported, skeletal muscle mass is not always correlated with physical activity or strength [37]. Thus, any extrapolation of the association between energy intake and skeletal muscle mass to improvement of muscle strength or physical activity may not be appropriate in this study.

To the best of our knowledge, this is the first study to investigate changes in total energy intake according to different levels of skeletal muscle mass separately in men and women from population-based data. The data suggest that an increase in SI index can be predicted based on increased total energy intake, although any change in skeletal muscle mass in response to energy or nutrient intake may vary by gender. The results highlight the need for the separate consideration of men and women in the prediction of skeletal muscle mass and relating factors. Further studies to identify the dietary patterns affecting skeletal muscle mass and to develop a gender-specific model for predicting skeletal muscle are warranted.

\section{CONFLICT OF INTEREST}

The authors declare no potential conflicts of interests.

\section{ORCID}

Bo Young Jang: https://orcid.org/0000-0001-5227-4327

So Young Bu: https://orcid.org/0000-0001-9801-5435

\section{REFERENCES}

1. Janssen I, Shepard DS, Katzmarzyk PT, Roubenoff R. The healthcare costs of sarcopenia in the United States. J Am Geriatr Soc 2004;52:80-5.

2. World Health Organization. World Report on Ageing and Health. Geneva: World Health Organization; 2015.

3. Poggiogalle E, Lubrano C, Sergi G, Coin A, Gnessi L, Mariani S, Lenzi A, Donini LM. Sarcopenic obesity and metabolic syndrome in adult caucasian subjects. J Nutr Health Aging 2016;20:958-63.

4. Stephens FB, Chee C, Wall BT, Murton AJ, Shannon CE, van Loon $\sqcup$, Tsintzas K. Lipid-induced insulin resistance is associated with an impaired skeletal muscle protein synthetic response to amino acid ingestion in healthy young men. Diabetes 2015;64:1615-20.

5. Slusher AL, Mock JT, Whitehurst M, Maharaj A, Huang CJ. The impact of obesity on pentraxin 3 and inflammatory milieu to acute aerobic exercise. Metabolism 2015;64:323-9.

6. Ryan AM, Power DG, Daly L, Cushen SJ, Ni BE, Prado CM. Cancerassociated malnutrition, cachexia and sarcopenia: the skeleton in the hospital closet 40 years later. Proc Nutr Soc 2016;75:199-211.

7. Shad BJ, Wallis G, van Loon $\sqcup$, Thompson JL. Exercise prescription for the older population: the interactions between physical activity, sedentary time, and adequate nutrition in maintaining musculoskeletal health. Maturitas 2016;93:78-82.

8. Reidy PT, Rasmussen BB. Role of ingested amino acids and protein in the promotion of resistance exercise-induced muscle protein anabolism. J Nutr 2016;146:155-83.

9. Smith Gl, Yoshino J, Stromsdorfer KL, Klein SJ, Magkos F, Reeds DN, Klein S, Mittendorfer B. Protein ingestion induces muscle insulin resistance independent of leucine-mediated mTOR activation. Diabetes 2015;64:1555-63.

10. Tinker LF, Sarto GE, Howard BV, Huang $Y$, Neuhouser ML, Mossavar-Rahmani $\mathrm{Y}$, Beasley JM, Margolis KL, Eaton CB, Phillips LS, Prentice RL. Biomarker-calibrated dietary energy and protein intake associations with diabetes risk among postmenopausal women from the Women's Health Initiative. Am J Clin Nutr 2011;94:1600-6

11. Kalyani RR, Tra Y, Egan JM, Ferrucci L, and Brancati F. Hyperglycemia is associated with relatively lower lean body mass in older adults. J Nutr. Health Aging 2014;18:737-43.

12. Blundell JE, Caudwell $P$, Gibbons $C$, Hopkins M, Naslund E, King NA, Finlayson G. Body composition and appetite: fat-free mass (but not fat mass or BMI) is positively associated with self-determined meal size and daily energy intake in humans. Br J Nutr 2012;107: 445-9.

13. Hopkins M, Finlayson G, Duarte C, Whybrow S, Ritz P, Horgan GW, Blundell JE, Stubbs RJ. Modelling the associations between fat-free mass, resting metabolic rate and energy intake in the context of total energy balance. Int J Obes (Lond) 2016;40:312-8.

14. Ferrando AA, Tipton KD, Bamman MM, Wolfe RR. Resistance exercise maintains skeletal muscle protein synthesis during bed rest. J Appl Physiol (1985) 1997;82:807-10.

15. Kalyani RR, Tra Y, Yeh HC, Egan JM, Ferrucci L, Brancati FL. Quadriceps strength, quadriceps power, and gait speed in older U.S. adults with diabetes mellitus: results from the National Health and Nutrition Examination Survey, 1999-2002. J Am Geriatr Soc 2013;61:769-75

16. Hughes VA, Frontera WR, Roubenoff R, Evans WJ, Singh MA. Longitudinal changes in body composition in older men and women: role of body weight change and physical activity. Am J Clin Nutr 2002;76:473-81.

17. Cermak NM, Res PT, de Groot LC, Saris WH, van Loon L. Protein supplementation augments the adaptive response of skeletal muscle to resistance-type exercise training: a meta-analysis. Am J Clin Nutr 2012;96:1454-64.

18. Okazaki K, Yazawa D, Goto M, Kamijo Yl, Furihata M, Gen-no H, Hamada $\mathrm{K}$, Nose $\mathrm{H}$. Effects of macronutrient intake on thigh muscle 
mass during home-based walking training in middle-aged and older women. Scand J Med Sci Sports 2013;23:e286-92.

19. Satia-Abouta J, Patterson RE, Schiller RN, Kristal AR. Energy from fat is associated with obesity in U.S. men: results from the Prostate Cancer Prevention Trial. Prev Med 2002;34:493-501.

20. Ferreira SR, Lerario DD, Gimeno SG, Sanudo A, Franco ப. Obesity and central adiposity in Japanese immigrants: role of the Western dietary pattern. J Epidemiol 2002;12:431-8.

21. Rosato V, Edefonti V, Parpinel M, Milani GP, Mazzocchi A, Decarli A, Agostoni C, Ferraroni M. Energy contribution and nutrient composition of breakfast and their relations to overweight in free-living individuals: a systematic review. Adv Nutr 2016;7:455-65.

22. Phillips SM. Nutritional supplements in support of resistance exercise to counter age-related sarcopenia. Adv Nutr 2015;6:452-60.

23. Janssen I, Heymsfield SB, Wang ZM, Ross R. Skeletal muscle mass and distribution in 468 men and women aged 18-88 yr. J Appl Physiol (1985) 2000;89:81-8.

24. Gallagher D, Heymsfield SB. Muscle distribution: variations with body weight, gender, and age. Appl Radiat Isot 1998;49:733-4.

25. Ministry of Health and Welfare (KR); The Korean Nutrition Society. Dietary Reference Intakes for Koreans 2015. Sejong: Ministry of Health and Welfare; 2016.

26. Han JE, Lee JY, Bu SY. The level of serum cholesterol is negatively associated with lean body mass in Korean non-diabetic cancer patients. Clin Nutr Res 2016;5:126-36.

27. Korea Centers for Disease Control and Prevention. Guidelines for Utilization of Raw Data from the Fifth Korea National Health and Nutrition Examination Survey (2010-2012). Cheongwon: Korea Centers for Disease Control and Prevention; 2012.

28. Studenski SA, Peters KW, Alley DE, Cawthon PM, McLean RR, Harris $T B$, Ferrucci L, Guralnik JM, Fragala MS, Kenny AM, Kiel DP, Kritchevsky SB, Shardell MD, Dam TT, Vassileva MT. The FNIH sarcopenia project: rationale, study description, conference recom- mendations, and final estimates. J Gerontol A Biol Sci Med Sci 2014;69:547-58.

29. Rural Development Administration (KR). Food Composition Table. 7th ed. Suwon: Rural Development Administration; 2006.

30. Cameron JD, Sigal RJ, Kenny GP, Alberga AS, Prud'homme D, Phillips $P$, Doucette S, Goldfield G. Body composition and energy intake - skeletal muscle mass is the strongest predictor of food intake in obese adolescents: the HEARTY trial. Appl Physiol Nutr Metab 2016;41:611-7.

31. McNeil J, Lamothe G, Cameron JD, Riou ME, Cadieux S, Lafreniere J, Goldfield G, Willbond S, Prud'homme D, Doucet E. Investigating predictors of eating: is resting metabolic rate really the strongest proxy of energy intake? Am J Clin Nutr 2017;106:1206-12.

32. Min HS, Kang JY, Sung J, Kim MK. Blood triglycerides levels and dietary carbohydrate indices in healthy Koreans. J Prev Med Public Health 2016;49:153-64.

33. Ha K, Kim K, Chun OK, Joung H, Song Y. Differential association of dietary carbohydrate intake with metabolic syndrome in the US and Korean adults: data from the 2007-2012 NHANES and KNHANES. Eur J Clin Nutr. Forthcoming 2018.

34. Kim K, Yun SH, Choi BY, Kim MK. Cross-sectional relationship between dietary carbohydrate, glycaemic index, glycaemic load and risk of the metabolic syndrome in a Korean population. Br J Nutr 2008;100:576-84.

35. Meyer KA, Kushi LH, Jacobs DR Jr, Slavin J, Sellers TA, Folsom AR. Carbohydrates, dietary fiber, and incident type 2 diabetes in older women. Am J Clin Nutr 2000;71:921-30.

36. Song SJ, Lee JE, Paik HY, Park MS, Song YJ. Dietary patterns based on carbohydrate nutrition are associated with the risk for diabetes and dyslipidemia. Nutr Res Pract 2012;6:349-56.

37. Rozenek R, Ward P, Long S, Garhammer J. Effects of high-calorie supplements on body composition and muscular strength following resistance training. J Sports Med Phys Fitness 2002;42:340-7. 